\title{
Retinal Arteriovenous Malformation (AVM): A Case Report
}

\author{
Poonam G*, Praveen G, Sumit G and Rakesh B \\ Department of Ophthalmology, Dr Baba Saheb Ambedkar Medical College \& \\ Hospital, India
}

*Corresponding author: Poonam Gupta, Department of Ophthalmology, Dr Baba Saheb Ambedkar Medical College \& Hospital, Rohini, New- Delhi-85, India, Email:

\begin{tabular}{|c|}
\hline Case Report \\
Volume 3 Issue 5 \\
Received Date: October 08, 2018 \\
Published Date: November 14, 2018 \\
DoI: 10.23880 /oajo-16000166 \\
\hline
\end{tabular}
dr.sumitgrover@gmail.com

\begin{abstract}
A retinal AVM is a rare, unilateral, nonhereditary congenital anomaly with variable presentation and variable visual involvement. Presentation can vary from subtle arteriovenous communications to marked dilation of the entire retinal vascular system. Most commonly involved areas are papillomacular and the superotemporal retina. We describe a case of 22 year old male patient presented with complaint of decreased vision in right eye. Fundus examination showed multiple dilated tortuous vessels involving whole of the Retina of right eye, including disc and macula. Left eye was within normal limits. No other systemic involvement was noted.

Detailed evaluation and further follow-up is necessary because of associated systemic conditions and CNS anomalies.

Keywords: Arteriovenous Malformation (AVM); Fundus Fluorescein Angiography (FFA); Wyburn-Mason Syndrome
\end{abstract}

\section{Introduction}

A retinal AVM is an infrequent, unilateral, congenital and sporadic anomaly. Presentation of AVM can vary from subtle arteriovenous communications that are scarcely visible on retinal examination to marked dilation of the entire retinal vascular system. Identification of arterial and venous components is intricate because of arterialization of the involved veins with extensive involvement [1]. Retinal AVMs are usually associated with normal visual acuity and are detected incidently during a routine eye examination. Both sexes are equally affected. Most commonly involved areas are papillomacular and the superotemporal retina. There may be presence of Single or multiple vascular anomalies in the fundus [2].

\section{Case Report}

\section{A 22 year old boy presented to OPD for routine}

checkup. On examination, BCVA in right eye was 20/80 while BCVA in left eye was 20/20. Anterior segment of both eyes were within normal limits. Fundus findings with indirect ophthalmoscope showed multiple dilated tortuous vessels involving whole of the fundus of right eye, including disc and macula. Fundus of left eye was within normal limits.

FFA of R/E revealed early filling and delayed emptying of anastomosing vessels but no leakage and no areas of capillary non-perfusion (Figure 1). FFA of left eye did not reveal any abnormal findings. A detailed history was also non-significant. Complete laboratory evaluations including hemogram, coagulation profile, ESR were also within normal limits. ECHO and MRI brain and orbit were also found unremarkable (Figure 2).

Patient was advised to follow up regularly. 



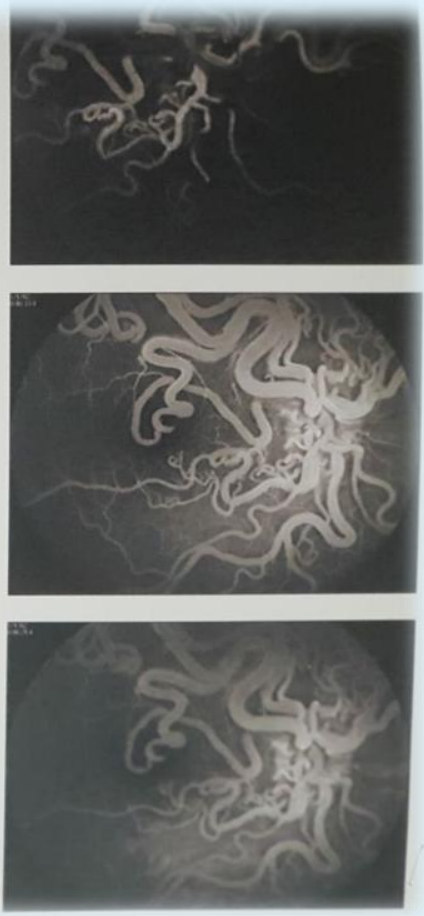

Figure 1: FFA of R/E revealed early filling and delayed emptying of anastomosing vessels but no leakage and no areas of capillary non-perfusion.

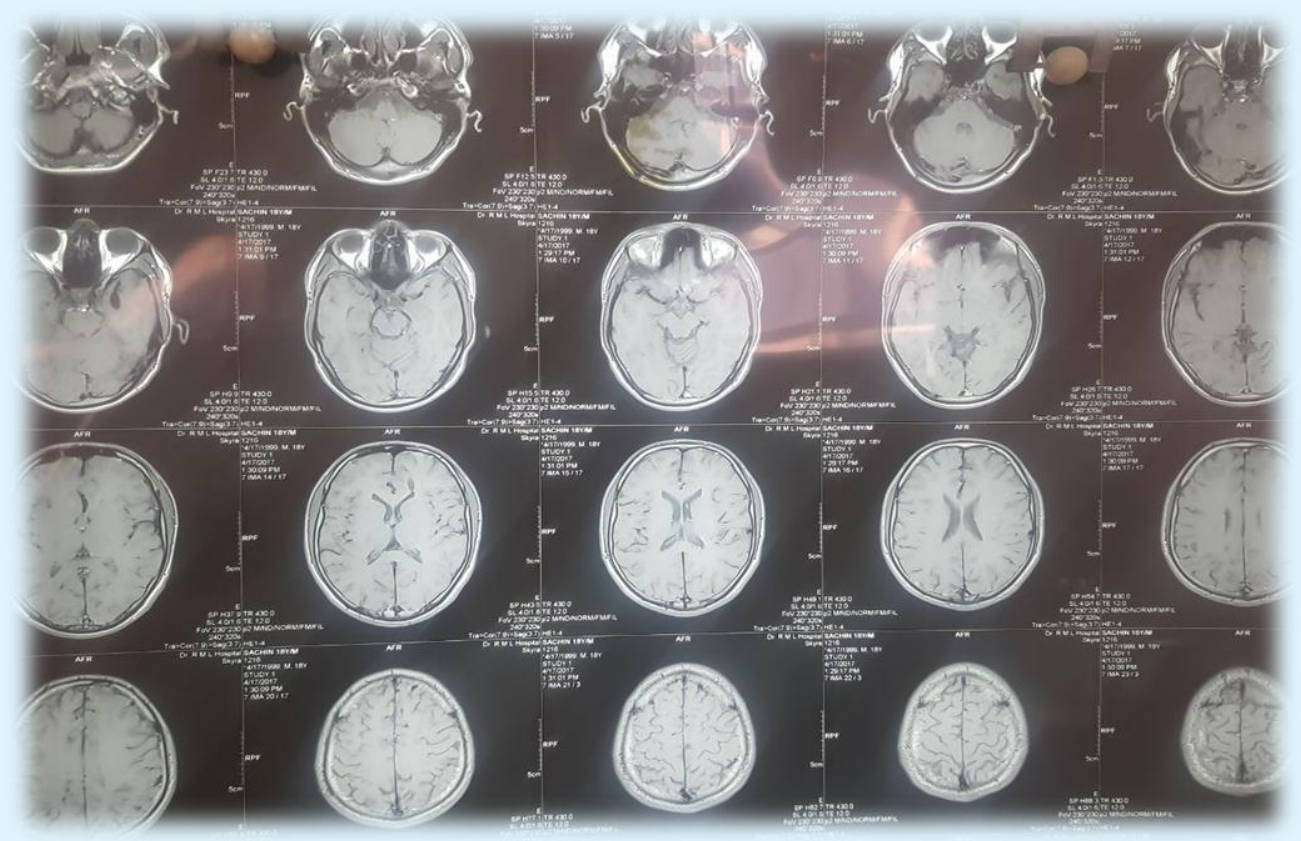

Figure 2: ECHO and MRI brain and orbit were also found unremarkable. 


\section{Open Access Journal of Ophthalmology}

\section{Discussion}

A retinal AVM is a rare, unilateral, nonhereditary congenital anomaly with variable presentation and variable visual involvement [1].
Retinal AVMs are classified into three groups (Table 1), depending on the intervening vascular system, the calibre of the connecting vessel, and the number and location of the malformations within the retina. Our case seems to be variant of type III though there is no intracranial involvement [3].

\begin{tabular}{|c|c|c|}
\hline Variant & Characteristics & Associations \\
\hline 1 & $\begin{array}{c}\text { Localized, well-compensated, intervening arteriolar or abnormal capillary plexus } \\
\text { between the communicating vessels }\end{array}$ & $\begin{array}{c}\text { Ocular or systemic } \\
\text { malformations unusual }\end{array}$ \\
\hline 2 & $\begin{array}{c}\text { Direct arteriovenous malformation without intervening vascular components } \\
\text { that may decompensate, leading to leakage of fluid (from slight leakage to } \\
\text { extensive retinal edema, exudates, and hemorrhages) }\end{array}$ & $\begin{array}{c}\text { Usually not associated } \\
\text { with intracranial } \\
\text { vascular malformations }\end{array}$ \\
\hline 3 & $\begin{array}{c}\text { Large and diffuse anastomosing channels, leading to difficulty in recognizing } \\
\text { arterial and venous components; degenerative changes in the retina and poor } \\
\text { vision }\end{array}$ & $\begin{array}{c}\text { Intracranial involvement } \\
\text { more likely than with } \\
\text { other variants }\end{array}$ \\
\hline
\end{tabular}

Table 1: Variants of Retinal Arteriovenous Malformation.

Retinal AVMs have been associated with intracranial and central nervous system (CNS) AV Malformations [1]. The causes of deteriorated Vision in patients with retinal AVMs are macular edema, macular hemorrhage, cystic degeneration in the retina, venous occlusive disease, retinal ischemia, neovascular glaucoma from the isolated retinal AVM or AVMs in the visual pathway $[2,4]$.

A congenital vascular abnormality in which AVMs of the visual pathway, face, and CNS coexist is called Wyburn-Mason syndrome; however, involvement of all three systems is not required for the diagnosis [4,5]. Usually AVMs are present in the midbrain, and occurrence of neurologic manifestations like cerebral or subarachnoid hemorrhage depends on the size and location of the malformations. Patients may present with variable signs of a midbrain lesion, hemiparesis or hemiplegia due to cerebral lesion, cerebellar dysfunction, or hydrocephalus; intellectual disturbances have also been reported. Seizures occur in only 5 percent of patients with retinal AVMs. Facial or oral vascular nevi and angiomas of the mandible, maxilla, palate, pharynx, and buccal mucosa can also occur $[1,6]$.

Retinal AVMs usually do not require treatment as most of them are static. Treatment may be required in cases of secondary complications e.g. Laser therapy for retinal edema and hard exudates in the fovea. Magnetic resonance imaging of the brain and orbit should be performed in patients with retinal AVMs because of the high probability for intracranial involvement. Neurosurgical consultation may be warranted if an intracranial AVM is identified; however, those AVMs are often inoperable because of their location deep in the midbrain, though embolization may be effective in some patients.

\section{References}

1. Wyburn-Mason R (1943) Arteriovenous aneurysm of mid-brain and retina, facial naevi and mental changes. Brain 66(3): 163-203.

2. Mansour AM, Walsh JB, Henkind P (1987) Arteriovenous anastomoses of the retina. Ophthalmology 94(1): 35-40.

3. Archer DB, Deutman A, Ernest JT, Krill AE (1973) Arteriovenous communications of the retina. Am J Ophthalmol 75(2): 224-241.

4. Brown DG, Hilal SK, Tenner MS (1973) WyburnMason syndrome. Report of two cases without retinal involvement. Arch Neurol 28(1): 67-69.

5. Ponce FA, Han PP, Spetzler RF, Canady A, Feiz-Erfan I (2001) Associated arteriovenous malformation of the orbit and brain: a case of Wyburn-Mason syndrome without retinal involvement. Case report. J Neurosurg 95(2): 346-349.

6. Ebert EM, Albert DM (2000) The phakomatoses. In: Albert DM, Jakobiec FA (Eds.), Principles and Practice of Ophthalmology. 2nd (Edn.), Philadelphia, Pa.: Saunders pp: 5117-5146. 


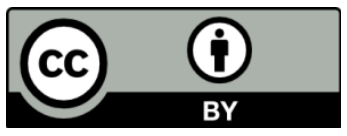

Poonam G, et al. Retinal Arteriovenous Malformation (AVM): A Case Report. J Ophthalmol 2018, 3(5): 000166. 